\title{
What is the Major Factors to Kill Bacterial Spores by Nitrogen Gas Plasma Sterilization
}

\section{Hideharu Shintani*}

Faculty of Science and Engineering, Chuo University, Tokyo, Japan

Many papers on gas plasma sterilization have ever been published so far and mostly done by physical researchers. Sterilization research is required knowledge chemistry, engineering and microbiology, so physical researchers 'research results are lack of microbiological and chemical aspects, so cannot reach the final purpose. After joining the microbiologist and chemist to gas plasma sterilization research, the content of the research is much advanced [1]. Current understanding on mechanism of gas plasma sterilization is still incomplete, but we knew what we do not know and what we need to clarify, so describing about what we need to clarify herein.

As shown in (Figure 1), it has been reported several sorts of sterilization factors to destroy bacterial spores. Among them they are atoms, molecules, minus or plus ions, photons, electrons, free radicals and metastables and UV. Among these UV and VUV contribution was denied by Kong et al. [2]. Free radicals are attractive factors, but their life period is too short (around a few $\mu \mathrm{s}$ ), therefore they may contribute, but not as a major factor. Ions or charged ones are trapped with the outer membrane of the bacterial membrane or spore outlayer, so charged ones are considered not to appropriate factors. In the same meaning, electrons are minus charged particle, so not major factors.

As a rest, we can consider about the contribution of the metastables. Among metastable, we find that lifetime of singlet Oxygen is 7s, so may be one of a candidate. How about the life time of $\mathrm{N}_{2}$ metastable is? As shown in (Figure 2), we can observe the $\mathrm{N}_{2}$ metastable by applying pulsed-amperometric discharge and we measure the lifetime of $\mathrm{N}_{2}$ metastable as a few s (experimentally $2 \mathrm{~s}$ ) in (Figure 3 ). So, we can estimate $\mathrm{N}_{2}$ or $\mathrm{O}_{2}$ metastables may be the most favorable candidates to inactivate bacterial spores.

However, we have a still problem to be resolved. Bacterial spore death is considered by hydration of dipicolic acid (DPA, Figure 4), so how can we connect $\mathrm{N}_{2}$ metastable to hydration of DPA. The last problem may be the most difficult to clarify. We are now speculating

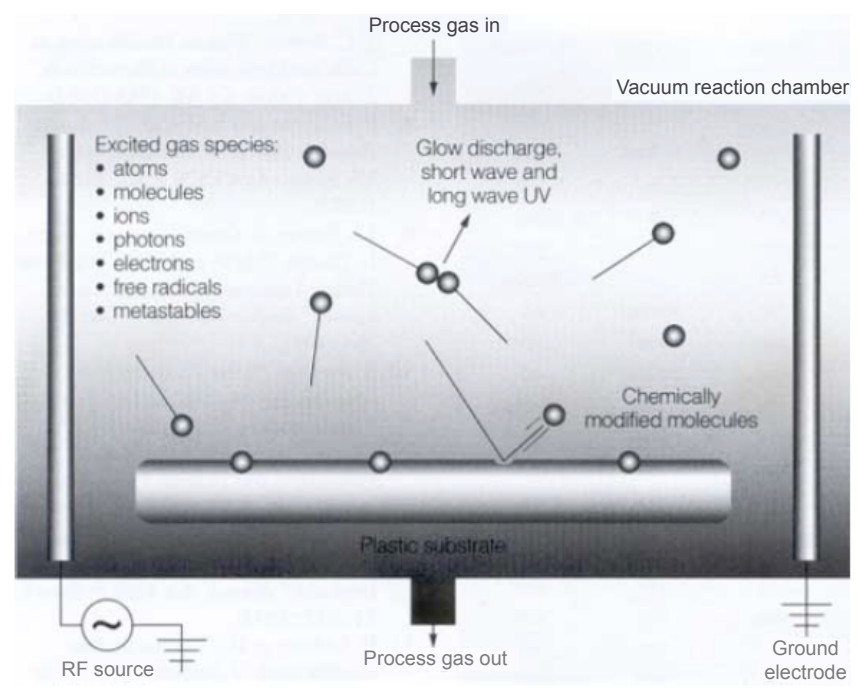

Figure 1: Several factors to connect gas plasma sterilization.

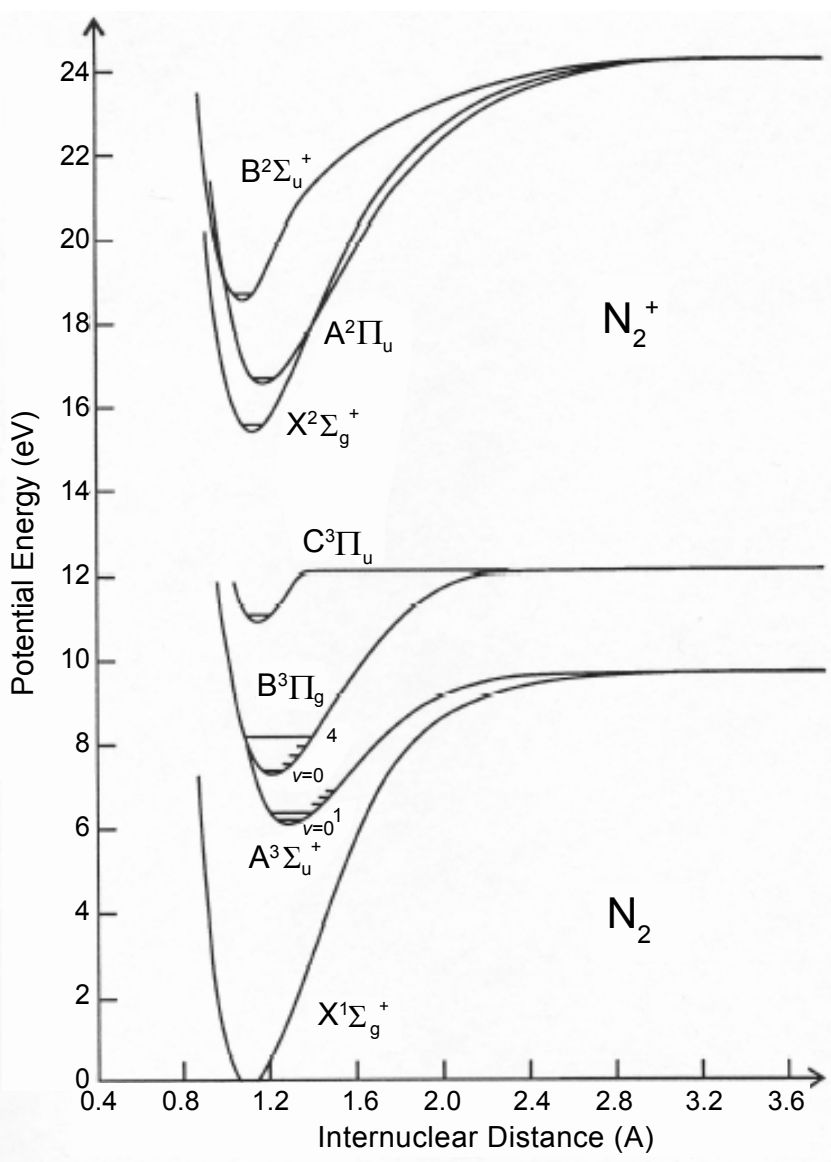

Figure 2: $\mathrm{N}_{2}$ gas metastable formation by pulsed amperometric discharge. The upper is the excited state and the lower the ground state.

the spore is attacked to metastables to produce pinhole and the water surrounded the bacterial spore may enter into the core from the pinhole. That may be the reason why bacterial spores would be killed with maintaining the figures [3]. The killing process may be caused within the spore, therefore figures of the dead spore are identical to those of the control. The last is only speculation, so we still need to further study to clarify the truth.

${ }^{*}$ Corresponding author: Hideharu Shintani, Faculty of Science and Engineering Chuo University, 1-13-27, Kasuga, Bunkyo, 112-8551, Tokyo, Japan, Tel: +81425922336, Fax: +81425922336; E-mail: shintani@mail.hinocatv.ne.jp

Received June 28, 2014; Accepted June 30, 2014; Published July 07, 2014

Citation: Shintani H (2014) What is the Major Factors to Kill Bacterial Spores by Nitrogen Gas Plasma Sterilization. Pharmaceut Reg Affairs 3: e134. doi:10.4172/2167-7689.1000e134

Copyright: () 2014 Shintani H. This is an open-access article distributed under the terms of the Creative Commons Attribution License, which permits unrestricted use, distribution, and reproduction in any medium, provided the original author and source are credited. 


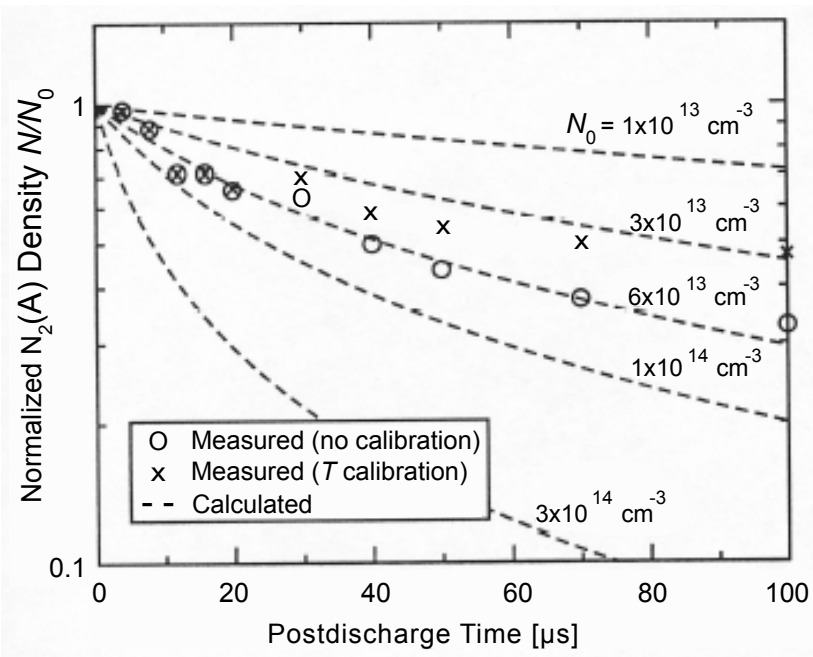

Figure 3: Life time of measured $\mathrm{N}_{2}$ metastable $\circ$ or $\times$ indicates measured life. Unit of $X$ axis is $\mu$ s, from this a few s can be a life time.

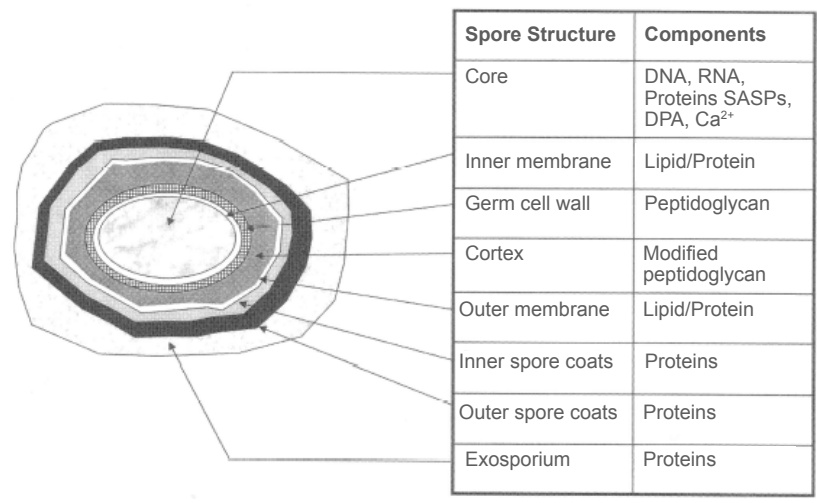

Figure 4: Structure of interior of bacterial spore DPA is dipicolic acid and in normal it exists as DPA $=\mathrm{Ca}$ (chelating).

\section{References}

1. Sakudo A and Shintani H (2011) Sterilization and Disinfection by Plasma, Sterilization Mechanisms, Biological and Medical Applications, NOVA Science Publishers, New York.

2. Xutao Deng, Jianjun Shi, Kong MG (2006) Physical mechanisms of inactivation of Bacillus subtilis spores using cold atmospheric plasma, IEEE Trans Plasma Sci 32: 1310-1316.

3. Shintani H, Shimizu N, Imanishi Y, Sekiya T, Tamazawa K, et al. (2007) Inactivation of microorganisms and endotoxins by low temperature nitrogen gas plasma exposure. Biocontrol Science 12: 131-143. 